\title{
A questão da unidade na forma e no sentido: implicações para os estudos textuais e gramaticais
}

Carmem Luci da Costa Silva*

\section{Resumo}

Este artigo tem como objetivo tratar do problema da unidade no texto "A forma e o sentido na linguagem", para, em um primeiro momento, abordar a importância da delimitação da unidade em uma linguística própria a Émile Benveniste e, em um segundo momento, considerar as implicações dessa delimitação para os estudos textuais e gramaticais da língua portuguesa, uma língua-idioma específica. $\mathrm{Na}$ primeira parte do artigo, é proposta a reflexão em torno da unidade presente em outros textos - "Os níveis da análise linguística" e "Semiologia da língua" -, colocados em relação com "A forma e sentido na linguagem" texto-base desta reflexão -, para constituir uma concepção de língua que abarque a teorização de linguagem proposta pelo linguista. A abordagem do problema da unidade na reflexão benvenistiana sobre língua permite, na segunda parte do estudo, uma discussão sobre as implicações da delimitação da unidade no domínio da língua em emprego - o da palavra - em relação com as unidades no domínio intralinguístico - o do signo - para os estudos textuais e gramaticais.

Palavras-chave: Forma e sentido. Gramática. Texto. Unidade.

\section{Palavras iniciais}

Este texto é originário da reflexão proposta para o $2^{\text {o }}$ Colóquio Leituras de Émile Benveniste, evento promovido pelos Programas de Pós-Graduação em Letras da Universidade de Passo Fundo e da Universidade Federal do Rio Grande do Sul e realizado em Passo Fundo, RS, de 9 a 10 de agosto de 2018. O convite para uma apresentação no colóquio desafiou-me a buscar mais respostas aos problemas de linguagem que tanto inquietavam Émile Benveniste.

O problema eleito para a reflexão neste artigo, que advém da reflexão apresentada no colóquio, é o da unidade. E o texto-base escolhido para empreender tal problematização é "A forma e o sentido na linguagem”, apresentado por

\footnotetext{
Docente do Departamento de Letras Clássicas e Vernáculas e do Programa de Pós-Graduação em Letras da Universidade Federal do Rio Grande do Sul. Pesquisa e orienta na área de Estudos da Linguagem, e seus principais temas de interesse são: aquisição da linguagem, estudo de texto e ensino de língua portuguesa nas abordagens enunciativas e argumentativas. E-mail: clcostasilva@hotmail.com
}

Data de submissão: set. 2018 - Data de aceite: out. 2018 http://dx.doi.org/10.5335/rdes.v14i3.8624 
Benveniste, em 1966, em um Congresso da Sociedade de Filosofia de Língua Francesa e publicado na revista Le Langage II, em 1967. "A forma e o sentido na linguagem" faz parte do livro Problemas de linguística geral II, obra publicada originalmente na França em 1974 e traduzida no Brasil em 1989.

Expor essa reflexão no colóquio e, agora, em artigo, guardadas as diferenças, envolve os sentimentos que assolaram Benveniste ao apresentar a sua discussão aos filósofos. Por estar diante de estudiosos da linguagem, ao sentimento de alegria de compartilhar esse espaço de troca de ideias, "mistura-se muita inquietude" (BENVENISTE, 1989a, p. 220 ${ }^{1}$ face ao fato de me dirigir a especialistas. No entanto, assim como Benveniste, encontro "algum encorajamento" no fato de o colóquio e este número da Revista Desenredo terem essa proposta de aprofundar a teorização sobre linguagem de Émile Benveniste com pesquisadores dispostos a divulgarem a reflexão que realizaram sobre os textos escolhidos do linguista, tornando suas propostas temas para o diálogo e $o$ debate. E assim concretizamos, como diz Benveniste, “[...] uma troca que pode ser de grande valia" (1989a, p. 220).

A abordagem do tema da forma e do sentido é realizada por Benveniste, como ele mesmo avisa, a partir do ponto de vista da Linguística e, portanto, fora de qualquer pressuposto filosófico. Além disso, o linguista alerta que aborda o problema da forma e do sentido não em nome da Linguística Geral ou dos linguistas, mas de seu ponto de vista linguístico: "Quem fala aqui o faz em seu nome pessoal e propõe pontos de vista que lhe são próprios" (BENVENISTE, 1989a, p. 221). Na introdução ao texto, o linguista também destaca o fato de que o domínio da linguagem que explorará será o da dita ordinária, não a linguagem poética, mas adverte que os esclarecimentos sobre a linguagem ordinária será de proveito, ou não, para a compreensão da linguagem poética também.

A partir disso, apresento duas pontuações: 1) o texto "A forma e o sentido na linguagem" desdobra-se sobre o ponto de vista próprio do linguista Benveniste, a partir do qual é possível derivar princípios para uma linguística benvenistiana, em uma teoria de linguagem que não se encerra, segundo meu ponto de vista, em uma teoria enunciativa; 2) o texto focaliza o tratamento da linguagem ordinária como possibilitando a compreensão da linguagem poética, o que permite que se estudem realizações individuais e coletivas ligadas ao exercício do discurso em diferentes práticas humanas.

Considerados esses pontos, concebo que uma linguística benvenistiana - uma linguística da linguagem, das línguas, da língua -, ao tomar para si a questão da forma e do sentido, tem, como principal problema, o da delimitação da unidade. E é justamente a delimitação da unidade que permite a Benveniste conceber a língua em dois domínios (do semiótico e do semântico) para propor 
a sua Linguística e é o que lhe permite ver a língua como sistema interpretante, considerando um ponto de vista semiológico, conforme depreende-se da leitura de "Semiologia da língua" (1969) e Últimas aulas no Collège de France (1968 e 1969) (2014). ${ }^{2}$

Flores (2013a), na obra Introdução à teoria enunciativa de Benveniste, insere, no segundo momento da teoria, três textos: "Os níveis da análise linguística" (1962/1964), que integra o PLG I, "A forma e o sentido na linguagem" (1966/1967) e "Semiologia da língua" (1969), que integram o PLG II. Esse agrupamento encontra respaldo, para Flores, no próprio Benveniste, que, ao abordar o uso dos termos semiótico e semântico em "Semiologia da língua", faz remissão aos textos "A forma e o sentido na linguagem" e "Os níveis da análise linguística", embrião dessas noções. Flores (2013a) agrupa esses textos também, principalmente, pela discussão sobre a forma e o sentido, noções vinculadas aos domínios semiótico e semântico. Ao trazer esses pontos, o autor também toca em vários aspectos relacionados ao problema da unidade, embora não se centre nesse problema, por não ser seu objetivo no capítulo do livro.

A discussão que apresento acerca do agrupamento desses três textos coloca em relevo a questão da unidade, focalizando como texto axial "A forma e o sentido na linguagem", por ser este, para usar uma expressão bakhtiniana, o "elo" central da corrente discursiva organizada por Benveniste sobre a forma e o sentido na linguagem. Esse texto retoma e sistematiza os dois modos de se conceber a língua, segundo "Os níveis da análise linguística" - duas linguísticas com caminhos que se cruzam, "[...] conjunto de signos formais e a manifestação da língua na comunicação viva" (BENVENISTE, 1995, p. 139), para tratar dos dois modos de ser língua, no semiótico e no semântico, cada qual visto na forma e no sentido. Por conter esses dois modos, justamente, a língua pode ser concebida como um sistema interpretante dos demais, conforme "Semiologia da língua".

É na determinação desses dois modos que o problema da unidade comparece. A consideração da unidade em uma linguística benvenistiana pode ter implicações no estudo das línguas-idiomas (línguas reais), no estudo da gramática de uma língua-idioma e no estudo de textos que se encontram nas práticas humanas de cada língua-idioma.

A partir dessas palavras iniciais, tratarei, no item seguinte, do problema da unidade em "A forma e o sentido na linguagem”, para, após, abordar as implicações dessa reflexão para os estudos gramaticais e textuais.

\section{A unidade em "A forma e o sentido na linguagem"}

Benveniste, ao se centrar no fato de que "[...] o próprio da linguagem é, antes de tudo, significar" (1989a, p. 222), defende que a significação não é qualquer 
coisa que lhe seja dada de acréscimo, mas é da própria natureza da língua como manifestação da linguagem. $\mathrm{O}$ linguista interessa-se pelas línguas reais, por isso argumenta que toda língua real realiza-se por meios vocais, que formam “[...] um conjunto de sons emitidos e percebidos, que se organizam em palavras dotadas de sentidos" (BENVENISTE, 1989a, p. 224). Essa afirmação o leva a se deparar com um duplo aspecto da linguagem, que se manifesta nas línguas: como organização e como uso. Em uma primeira aproximação, retoma Saussure para pensar no signo.

A noção de signo integra, para Benveniste, no estudo da língua, a noção muito geral de significação. Ainda que a noção de signo seja central para pensar a natureza da língua, Benveniste vê que ela, juntamente com a distinção língua-fala, não dá conta da análise da língua como sistema significativo (significante), buscando algo mais ("ir além"). E assim, precisamente, Benveniste situa a problemática da unidade no sistema: "o signo é a unidade semiótica". Ele sublinha que essa proposição não está em Saussure porque talvez este a considerasse "[...] como uma evidente decorrência" (BENVENISTE, 1989a, p. 224). Ao conceber o signo como unidade semiótica, adverte que ele faz parte de uma dupla relação, cuja explicitação é necessária: como unidade semiótica e como dependente da ordem semiótica. A partir dessas pontuações, o linguista busca delimitar a sua proposta de linguística com o esta- tuto de ciência, incluindo uma explicação para a significação estar na natureza da linguagem e, portanto, da língua e das línguas:

Toda disciplina que visa adquirir o estatuto de ciência deve inicialmente definir suas constantes e suas variáveis, suas operações e seus postulados, e antes de tudo dizer quais são suas unidades. Nas ciências da natureza, as unidades são em geral porções idênticas convencionalmente recortadas de um contínuo específico; há assim unidades quantitativas, idênticas, substituíveis, em cada disciplina da natureza. A linguagem é bem outra coisa, ela não releva do mundo físico; ela não é nem do contínuo, nem do idêntico, mas bem ao contrário, do descontínuo e do dissemelhante. É por isso que ela não se deixa dividir mas decompor; suas unidades são elementos de base e de número limitado, cada um diferente do outro, e suas unidades se agrupam para formar novas unidades, e estas por sua vez poderão formar outras ainda, de um nível cada vez mais superior. Ora, a unidade particular que é o signo tem por critério um limite inferior: este limite é o da significação. A unidade, diremos nós, será entidade livre, mínima em sua ordem, não decomponível em uma unidade inferior que seja ela mesma um signo livre. É então signo a unidade assim definida, dependente da consideração semiótica da língua (BENVENISTE, 1989a, p. 225).

Não podemos deixar de pontuar a preocupação de Benveniste com a delimitação da unidade, questão central para propor uma linguística que considere forma e sentido na organização da língua. A delimitação da unidade como signo envolve a relação entre níveis - o inferior e o superior. Essa unidade é signo quando vista como dependente da consideração semiótica. 
Esse trecho, além de definir a unidade da linguística, traz a explicação do modo como Benveniste concebe a unidade no domínio semiótico, possível de dissociar e de integrar, num diálogo bastante grande com "Os níveis da análise linguística". E é a delimitação da unidade como signo, porque dependente da ordem semiótica, que coloca a língua como principal sistema semiológico, fato atestado em "Semiologia da língua", quando também mostra preocupação com a unidade, ao afirmar ser "[...] evidente que a noção de UNIDADE está no centro da problemática que nos ocupa" (BENVENISTE, 1989c, p. 57, destaque do autor). E pontua:

[...] todo sistema significante deve se definir por seu modo de significação. Um tal sistema deve então designar as unidades que coloca para produzir o "sentido" e especificar a natureza do "sentido" produzido (BENVENISTE, 1989c, p. 58).

A partir disso, o linguista propõe, no texto "Semiologia da língua", duas ques-

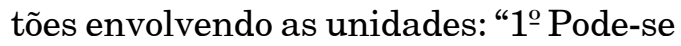
reduzir a unidades todos os sistemas semióticos? 2 ${ }^{\circ}$ ) Estas unidades, nos sistemas onde existem, são SIGNOS?" (BENVENISTE, 1989c, p. 58, destaque do autor). Responde às questões, afirmando que: "[...] a língua é feita de unidades, estas unidades são signos”. E pergunta: e quanto aos outros sistemas semiológicos? Defende, na sequência, ser a língua composta de um sistema de unidades significantes partilhadas, reconhecidas no uso nativo, diferentemente de outros sistemas. Por isso,
[...] a significância da língua [...] é a significância mesma, fundando a possibilidade de toda a troca e também de toda a comunicação, e também de toda a cultura (BENVENISTE, 1989c, p. 60).

Aqui está estabelecida a relação entre os três textos, nos quais, segundo meu ponto de vista, Benveniste envolve-se com o problema da unidade, ora para defini-la na organização da língua como sistema de signos possíveis de serem dissociados e integrados - caso de "Os níveis" -, ora para delimitá-la como signo ou como palavra nos dois modos de ser língua, no semiótico e no semântico - caso de "A forma e o sentido" -, ora para delimitar a língua como principal sistema semiológico em relação a outros sistemas - caso de "Semiologia da língua". Em todos esses textos, Benveniste dedica-se a refletir sobre a unidade para desenvolver uma concepção de língua própria à sua teorização de linguagem.

O linguista, para tratar do signo como dependente da ordem semiótica, em "A forma e o sentido na linguagem", destaca que uma das teses mais importantes de Saussure foi ter colocado a língua como um dos ramos da semiologia, mas adverte que foi o infortúnio e a glória de Saussure ter descoberto o princípio da semiologia meio século antes de seu tempo, fato que abriu caminho para a descrição das unidades semióticas, caracterizadas na forma e no sentido, já que o signo é unidade bilateral por natureza, constituído por significante e significado. A consideração da natureza do signo como unidade bilateral enca- 
minha Benveniste a propor observações sobre um e outro desses dois aspectos.

Ao considerar o significante, Benveniste trata-o como "aspecto formal da entidade chamada signo" (1989a, p. 225), concebendo que toda forma linguística é constituída de unidades sonoras, chamadas fonemas. A análise semiótica, alerta o linguista, exige que se introduza, antes do nível dos fonemas, o nível da estrutura fonemática do significante. $\mathrm{O}$ trabalho de delimitar as unidades como parte do inventário da língua implica considerar a função distintiva no interior dessa estrutura fonemática. Após examinar a unidade fonema, no interior do significante e como ligada ao nível de uma estrutura fonemática de traços que possibilitam a caracterização formal do significante com função distintiva no sistema, Benveniste aborda um plano distinto dos fonemas, o plano dos componentes formais, instaurando, sob a consideração semiótica, classes particulares: dos semiolexemas - signos lexicais livres -, dos semiocategoremas - subsignos classificatórios (prefixos, sufixos etc.). Com isso, traz para a discussão o modo como os signos se engendram em flexões e derivações para ligar classes inteiras de significantes e assegurar grandes unidades, superiores às unidades individuais. Vemos Benveniste integrando fonemas (fonologia) e morfemas (morfologia) para pensar o aspecto formal do significante, que, ao integrar um nível superior, recebe seu sentido em uma unidade mais alta. Ao considerar a função distintiva das unidades em cada nível e a integração de unidades entre níveis, o linguista prevê sentido para as unidades formais. É forma e sentido no significante.

Ao considerar o significado, Benveniste destaca o uso nativo da língua:

[...] o signo se define como unidade semiótica se ele é dotado de significação na comunidade daqueles que fazem uso de uma língua (BENVENISTE, 1989a, p. 227).

E retorna à semiologia:

Em semiologia, o que o signo significa não dá para ser definido. Para que um signo exista, é suficiente e necessário que ele seja aceito e se relacione de uma maneira ou de outra com os demais signos (BENVENISTE, 1989a, p. 227).

O linguista chama atenção para $o$ fato de que, para significar, um signo precisa ser reconhecido e se relacionar com outros. Significa ou não? Existe ou não? Destaca, como critérios de existência da unidade como signo, o uso e a identificação. Esse é o critério do domínio semiótico: a identificação no interior e no uso da língua. No domínio intralinguístico, está em jogo a identificação das unidades como distintivas em relação às outras. Portanto, é a partir dessa identificação de distintividade que as unidades são consideradas significativas na língua. É no uso que ocorre a identificação da unidade como tendo existência. Quem está no centro dessa identificação? O linguista responde: "A comunidade daqueles que fazem uso da língua” (BENVENISTE, 1989a, p. 227). 
Pensar uma gramática como uma organização semiótica da língua é considerar alguns aspectos: 1) a dissociação (forma) e a integração (sentido) para delimitar unidades na relação entre níveis (podemos pensar em fonologia e morfologia, por exemplo, como estudos integrados a partir de Benveniste); 2) o falante e a comunidade linguística como critérios de descrição por meio da identificação das unidades em uso: "[...] o que não é usado não é signo, fora do uso o signo não existe" (BENVENISTE, 1989a, p. 227).

A natureza semiótica da linguagem, para Benveniste, envolve os comportamentos que se institucionalizaram na vida social, com entidades de dupla face, conforme o signo linguístico. " $\mathrm{E}$ esta faculdade semiótica comum compõe, para cada conjunto, um sistema que aliás, em sua maior parte, resta ainda estudar" (BENVENISTE, 1989a, p. 228), uma espécie de anúncio para um estudo semiológico que coloca a língua em relação com outros sistemas.

Para além das relações entre signos, o linguista se pergunta: mas e a frase? Qual sua função na língua? Em "Os níveis", Benveniste já havia anunciado: "Com a frase transpomos um limite, entramos num novo domínio" (BENVENISTE, 1995, p. 137). Em "A forma e o sentido", pontua: “[...] está aí, em nossa análise, um ponto crucial" (BENVENISTE, 1989a, p. 228). E complementa: “[...] pensamos que o signo e a frase são dois mundos distintos e que exigem descri- ções distintas" (BENVENISTE, 1989a, p. 229). Instaura, assim, uma divisão fundamental, distinta da de Saussure, de linguagem como língua e fala, para propor dois domínios da língua - semiótico e semântico -, cada um articulado em forma e sentido. Há, por isso, para Benveniste, a língua como semiótico e a língua como semântico, modos que permitem ao locutor/falante significar e comunicar.

Qual a unidade do domínio semântico? Esse domínio envolve a relação homem-homem, homem-mundo, com transmissão de informação, imposição de adesão, busca de resposta, enfim lugar de integração do homem à sociedade, de adequação ao mundo, de organização do pensamento e da consciência.

"Com o signo tem-se a realidade intrínseca da língua; com a frase liga-se às coisas fora da língua" (BENVENISTE, 1989a, p. 230). No signo, como destacado anteriormente, forma e sentido lhe são inerentes, porque se vinculam ao significante e ao significado. Já o sentido da frase implica referência à situação de discurso e à atitude do locutor. $\mathrm{E}$ é com base nesse quadro geral que Benveniste passa a delimitar as noções de forma e de sentido sob o enfoque semântico. Embora a expressão semântica seja a frase, por revelar o intentado/intencionado ${ }^{3}-0$ querer dizer do locutor, a atualização linguística do pensamento -, a unidade do semântico não é a frase. Do semiótico ao semântico, há uma mudança radical; $\mathrm{e}$ as noções de forma e de sentido passam 
a ser revistas pelo linguista em novas indagações e problematizações.

Como o sentido se realiza no semântico? Pela conexão, pelo sintagma. Benveniste pergunta e responde: "Qual será a unidade semântica? - Simplesmente, a palavra" (BENVENISTE, 1989a, p. 230, grifo nosso). Benveniste chama a atenção para a posição funcional intermediária da palavra (decompor-se em unidades inferiores e compor uma unidade superior mais alta, a frase), em "Os níveis da análise”, texto no qual se preocupa em usar o termo por ser desacreditado, mas, ao mesmo tempo, insubstituível. Em "A forma e o sentido", também destaca o fato de a natureza da palavra ter sido objeto de tanto debate e tantas definições - "[...] sobre isso escreveram-se livros inteiros" (BENVENISTE, 1989a, p. 230). No entanto, depois disso, concebe que

[...] a palavra reencontra assim sua função natural, como unidade mínima da mensagem e como unidade necessária da codificação do pensamento (BENVENISTE, 1989a, p. 230).

Pela palavra, unidade da frase, chegase à ideia que a frase exprime, ao seu sentido:

[...] este sentido se realiza formalmente na língua pela escolha, pelo agenciamento de palavras, por sua organização sintática, pela ação que elas exercem umas sobre as outras (BENVENISTE, 1989a, p. 230).

Mais adiante, o linguista afirma: o sentido da frase é a sua ideia e o sentido da palavra é o seu emprego. E a referência da frase? É
[...] o estado de coisas que a provoca, a situação de discurso ou de fato a que ela se reporta e que nós não podemos jamais prever ou fixar (BENVENISTE, 1989a, p. 231).

E assim Benveniste toca na confusão frequente entre sentido e referência ou entre referente e signo, discussões vãs, segundo ele, porque envolvem o que se chama de princípio de arbitrariedade do signo. A frase é um acontecimento diferente, que existe no instante em que é produzida. Ela não pode comportar emprego, enquanto a palavra não tem senão empregos. Tomar uma entidade lexical como signo ou como palavra é, para o linguista, realçar estatutos diferentes, que resultam em consequências distintas, visto as entidades lexicais, se tomadas como palavras, serem consideradas na sintagmatização e produzirem sentidos implicados nas condições de emprego, enquanto, se tomadas como signos, serem vistas como apresentando um sentido partilhado no uso nativo e como compostas de unidades inferiores.

Nessa linha de reflexão, Benveniste defende que o sentido da frase está na totalidade da ideia percebida por uma compreensão global; a forma se obtém pela dissociação analítica dos enunciados, processada até as unidades semânticas, as palavras, que não podem mais ser dissociadas sem deixar de preencher a sua função. Assim, com a decomposição de unidades no semântico, chega-se à palavra; no semiótico, chega-se ao fonema. A entidade lexical, se tomada como signo, tem sentido genérico, não circunstancial; se tomada como palavra, é determinada 
em relação ao contexto de situação, a partir do qual adquire sentido particular e circunstancial.

A partir desse raciocínio, Benveniste aborda a relação entre o pensamento e uma língua-idioma, argumentando que a conversão do pensamento em discurso envolve o assujeitamento à estrutura formal de um idioma considerado, isto é, à organização tipológica que, segundo a língua, faz predominar tanto o gramatical quanto o lexical. Por isso, afirma que os dois sistemas, semiótico e semântico, se superpõem na língua tal como a utilizamos, porque, na base, há o sistema semiótico, organização dos signos segundo o critério de significação, incluindo as subunidades. Sobre esse fundamento semiótico, a língua-discurso constrói uma semântica própria, uma significação intentada/intencionada, produzida pela sintagmatização das palavras, em que cada palavra retém algo de um sentido partilhado - "pequena parte do valor que tem enquanto signo" (BENVENISTE, 1989a, p. 234) - e a outra parte da palavra adquire um sentido próprio e particular ao contexto de emprego.

Nessa síntese final, Benveniste defende ser impossível conceber uma língua com semiótico sem semântico ou com semântico sem semiótico. No entanto, chama a atenção para o fato de ser possível efetuar descrições distintas para cada unidade segundo o domínio no qual está encaixada, se é tomada como signo ou como palavra. Em outros termos, o linguista adverte o seguinte:
[...] é necessário traçar uma distinção no interior do domínio semântico entre a multiplicidade indefinida de frases possíveis, quer por sua diversidade, quer por sua possibilidade de se definirem umas em relação às outras, e o número sempre limitado, não só de lexemas utilizados como palavras, mas também dos tipos de esquemas sintáticos a que necessariamente a linguagem recorre. Este é o duplo sistema, constantemente em ação na língua, e que funciona tão velozmente, de um modo tão sutil, que exige um grande esforço de análise e um longo esforço para dele se desprender, se se quer separar o que é do domínio de um e do outro. Mas no fundo está o poder significante da língua, que é anterior ao dizer qualquer coisa (BENVENISTE, 1989a, p. 234).

Nessa linha, Benveniste fecha o texto reconduzindo-se ao seu ponto de partida, ou seja, à noção de significação, e conclui, a partir da fala misteriosa de Heráclito, que a linguagem não diz, nem oculta, mas significa.

Com esse passeio pelas palavras de Benveniste, como se pode pensar os estudos gramaticais e textuais, considerando a unidade no universo do signo e no da palavra? É a aventura a que me proponho a abordar na sequência desta reflexão.

\section{As unidades em forma e sentido: implicações para os estudos textuais e gramaticais}

Na chamada do colóquio, os proponentes lançam um convite e uma convocação: retomar o debate em torno da obra de Benveniste para projetar novas perspectivas. A resposta a essa convocação 
deveria ser realizada pela escolha de um texto do linguista, que cada participante considerasse fundamental para $o$ desenvolvimento da teoria da linguagem desse linguista.

Ao aceitar o convite e ao propor um estudo de "A forma e o sentido na linguagem", eu o fiz por acreditar ser um dos textos-chave para uma concepção de linguagem e de língua em Benveniste, que tem efeitos tanto em sua abordagem linguística quanto em sua abordagem semiológica. Além disso, é um texto que mostra como o pressuposto antropológico de $O$ homem na linguagem e $O$ homem na língua está implicado nos dois modos de ser língua, no semiótico e no semântico. Isso porque a língua somente existe como domínio semiótico devido ao fato de que as unidades são identificadas como distintivas na relação e como existentes no uso pelos falantes pertencentes a uma determinada comunidade. Já no domínio semântico, a língua proporciona a integração entre humanos e entre os humanos e a sociedade. Com isso, o humano está implicado como falante de uma comunidade, que partilha de um semiótico que lhe permite identificar a sua língua a cada vez que essa língua comparece como semântico - como língua-discurso -, e o humano está implicado em uma atitude própria que produz sentido e referência a cada vez que coloca o seu discurso como função mediadora entre outros humanos e entre ele e o mundo, para produzir uma semântica própria.

A partir dessas considerações, concebo o artigo "A forma e o sentido na linguagem" como um texto que abre perspectivas e que permite, por meio de deslocamentos, implicações que vão além do que já foi proposto e publicado para os estudos gramaticais e textuais. Por isso, retomo a interessante entrevista publicada no início do $P L G$ II, intitulada "Estruturalismo e linguística" (1989b), na qual Benveniste discute as concepções que permeiam perspectivas empiricistas e mentalistas, ora centradas em dados, ora centradas no pensamento. Ele coloca que,

[...] a partir do momento em que se trata do homem que fala, o pensamento reina e o homem está inteiramente no seu querer falar, ele é a sua capacidade de fala (BENVENISTE, 1989b, p. 19).

Com a ideia de fala e pensamento em relação, o linguista parece desfazer a ideia de que se vai ou para o dado ou para a mente. E complementa: "Trata-se antes de tudo da língua como organização e do homem como capaz de organizar sua língua" (BENVENISTE, 1989b, p. 19). Considerar essa afirmação leva muitos a se voltarem para Chomsky, que responde a essa formulação "de modo técnico e algébrico", conforme afirma Benveniste a Pierre. Como Benveniste responde a essa afirmação sem tecnicismo e sem álgebra?

Aventuro-me a dizer que uma das respostas a essa questão está no texto "A forma e o sentido na linguagem", também citado na entrevista, quando o linguista volta a afirmar que o semiótico envolve o fato de a unidade ser reconhecida como tendo ou não sentido no universo intralinguístico e que o semântico envolve o encadeamento e o sentido 
resultante da circunstância, em um universo para além do intralinguístico.

A partir do estudo de "A forma e o sentido", parece-me haver possibilidades de novos estudos em Benveniste, considerando-o como um linguista da linguagem, em uma linguística que inclui a sua teoria da enunciação, mas não se encerra nela. Nessa perspectiva, considero que, prospectivamente, esse texto possibilita um estudo gramatical que leve em consideração a organização de uma língua-idioma, conforme final de "A forma e o sentido", e que considere o fundamento semiótico da língua-discurso de um idioma $\mathrm{X}$ como produzindo uma semântica própria, com a delimitação de unidades, na imbricação de domínios.

Ao se considerar a unidade como signo, pode-se delimitá-la na integração entre os níveis, para propor um estudo fonológico e morfológico a partir de Benveniste. E, é claro, ao considerar a entidade lexical fora do signo, passa-se a considerar a palavra na frase em um estudo sintático. A dissociação das palavras encaminha a que se chegue às formas inferiores, que adquirem sentido na identificação da distintividade no uso em relação a outras unidades. Já a integração permite que se olhe para a palavra em emprego e para o sentido global da frase. Com isso, pode-se produzir um estudo gramatical em sintaxe e semântica de modo integrado.

Como é o homem falante quem está no centro da organização da língua, jamais se poderia pensar em um estudo da fonologia, da morfologia e da sintaxe sem considerar que é o falante/o locutor quem identifica as unidades, percebe distintividade nas relações e, portanto, quem atribui sentido a essas unidades. E é esse locutor quem agencia essas unidades em frases. Seria, portanto, uma gramática centrada no falante em seus dois modos de estar na língua: como quem partilha formas e sentidos em uma comunidade e como quem produz formas e sentidos singulares em seus discursos. É claro que, nesse caso, haveria uma gramática com os dois modos de ser língua implicados no uso nativo.

Parece-me ser possível propor um estudo gramatical da língua portuguesa, considerando a sua organização fonológica, morfológica e sintática, tendo o semantismo (sentido) como elemento transversal, conforme Flores (2013b), e o falante como organizador das unidades. Uma gramática que considere o fato de que os dois domínios, semiótico e semântico, estão superpostos na língua-discurso, condição de o falante produzir uma semântica própria, que carrega o sentido partilhado das unidades do semiótico e o sentido singular das palavras agenciadas no discurso. Nesse caso, a gramática seria a organização de uma língua-idioma em forma e sentido. E o homem como o capaz de organizar essa gramática a cada uso em forma e sentido. Tem-se, assim, as implicações da reflexão sobre "A forma e o sentido" em um estudo gramatical da língua portuguesa, que inclua uma reflexão sobre as diferentes unidades, o fonema, o morfema, a palavra lexical.

É com a frase e o discurso que vemos a língua em sua função mediadora entre 
o homem e o mundo. Trata-se da atualização de um querer dizer que comunica a experiência, que suscita resposta, enfim, que integra indivíduo e sociedade. Nesse caso, a grande implicação para um estudo textual, já amplamente desenvolvido em Benveniste, é o de olhar o sentido global do discurso e o sentido da palavra em emprego. No entanto, os estudos textuais, a partir de "A forma e o sentido na linguagem", também podem explorar outras questões: como, pelo domínio semântico, impomos a adesão de outro? Como o sentido de uma palavra, que é o seu emprego, pode ser concebido, se considerarmos a ação de uma palavra sobre a outra? E se considerarmos a posição de uma palavra em relação à outra? E se considerarmos a ação do sufixo sobre o radical? De um prefixo sobre o radical? São texto e gramática se implicando. São semiótico e semântico operando na análise. Como diz Benveniste, em resposta a Piguet, na entrevista no final de "A forma e o sentido", é necessário, metodologicamente, olhar para as diferenças entre semiótico e semântico, para que se avance por linguísticas diferentes e, eu diria, para olhar como as unidades de cada domínio funcionam, mas vendo, em seguida, "como elas [as linguísticas diferentes] podem se juntar e articular" (BENVENISTE, 1989a, p. 240). É nessa articulação que ocorre, a partir do semântico, que podemos propor estudos gramaticais e textuais com base em "A forma e o sentido". Essa articulação exige "um aparelho conceitual próprio", visto um "hiato" separar os dois domí- nios, conforme alerta Benveniste em a "Semiologia da língua".

Olhar para um texto, nessa acepção, que envolve o global e o analítico, é ver como, no discurso, as formas agem umas sobre as outras na busca de adesão e resposta do outro, em que há condições para "a geração de frases", como Benveniste afirma a Ricouer, também na entrevista que fecha o texto "A forma e o sentido na linguagem”. Há esquemas e mecanismos na produção de frases? Como mudamos de um modo de dizer a outro? Chomsky responde a isso por meio de uma sintaxe, por formas axiomáticas e matemáticas, diz Benveniste em resposta a Ricouer. Esses esquemas e mecanismos estão, para Benveniste, no semântico. Se estão no semântico, apresentam-se em textos, que estão na sociedade com a sua cultura. Por isso, o fechamento da entrevista concedida aos filósofos parece abrir um estudo de texto que considera que:

$\mathrm{Na}$ linguagem unifica-se esta dualidade de homem e de cultura, de homem e de sociedade, graças à propriedade de significação, de que tentamos desentranhar a natureza e o domínio (BENVENISTE, 1989a, p. 242).

Talvez se possa pensar em estudar o texto como objeto de linguagem, não só de língua, para pensar verbal e não verbal tão presentes nas mídias da contemporaneidade. Qual seria a unidade se não mais considerarmos somente a língua, mas a linguagem em textos? Talvez essa seja uma questão a ser pensada de um ponto de vista semiológico, não mais linguístico. Deixemos suspenso por ora esse problema... 


\section{Palavras finais}

Com este artigo, procurei tratar do problema da unidade no texto "A forma e o sentido na linguagem", para, em um primeiro momento, abordar a importância de sua delimitação em uma linguística própria a Émile Benveniste e, em um segundo momento, considerar as implicações da delimitação da unidade para os estudos textuais e gramaticais da língua portuguesa, uma língua-idioma específica. Na primeira parte do artigo, a reflexão em torno da unidade presente em outros textos - "Os níveis da análise linguística" e "Semiologia da língua" -, colocados em relação com "A forma e o sentido na linguagem", possibilitou-me pensar a unidade nos domínios semiótico - do signo - e semântico - da frase e do discurso, que tem como unidade a palavra.

A abordagem sobre o problema da unidade na teorização sobre língua permitiu-me, na segunda parte do estudo, a discussão sobre as implicações da delimitação da unidade no domínio da língua em emprego - da palavra - em relação com as unidades no domínio intralinguístico - do signo - para os estudos textuais e gramaticais.

Os desafios dos proponentes do colóquio, que me convocaram a atualizar palavras no discurso da apresentação e, depois, neste artigo, possibilitaram que eu empreendesse um feliz reencontro com palavras de Benveniste em "A forma e o sentido na linguagem”, para pensar que a Linguística benvenistiana possibilita uma linguagem que serve para viver, porque comporta uma reflexão sobre linguagem que "se apoia sobre línguas reais", conforme defende no prefácio do PLG I. Neste final, eu completaria que a Linguística benvenistiana se apoia no falante como quem organiza a sua língua para produzir discurso. E é nesse lugar de organização da língua pelo falante que, como pesquisadores e professores de língua materna, podemos pensar como gramática e texto, presentes nas realizações individuais e coletivas ligadas ao exercício do discurso em língua portuguesa, significam.

\section{La question de l'unité dans la forme et dans le sens : implications pour les études textuelles et grammaticales}

\section{Résumé}

Cet article a pour but de traiter du problème de l'unité dans le texte " La forme et le sens dans le langage " afin d'aborder, dans un premier moment, l'importance de la délimitation de l'unité dans une Linguistique propre à Émile Benveniste et, dans un deuxième moment, considérer les implications de cette délimitation pour les études textuelles et grammaticales de la langue portugaise, une langue-idiome spécifique. Dans la première partie de l'article, on propose la réflexion autour de l'unité présente dans d'autres textes - « Les niveaux de l'analyse linguistique » et "Sémiologie de la langue »-, mis en relation avec « $\mathrm{La}$ forme et le sens dans le langage »- 
texte-base de la réflexion ici proposée - pour constituer une conception de langue qui inclut la théorisation du langage proposée par le linguiste. L'approche du problème de l'unité dans la réflexion benvenistienne sur la langue permet, dans la deuxième partie de l'étude, une discussion à propos des implications de la délimitation de l'unité dans le domaine de la langue en emploi - celui du mot - en rapport avec les unités du domaine intralinguistique - celui du signe - pour les études textuelles et grammaticales.

Mots-clé: Forme et sens. Grammaire. Texte. Unité.

\section{Notas}

1 As obras Problemas de linguística geral I e Problemas de linguística geral II serão referidas, no decorrer do artigo, como, respectivamente, $P L G$ $I$ e $P L G I I$. As edições originais francesas são de 1966 e 1974, respectivamente. No Brasil, foram publicadas em 1995 (PLG I) e 1989 (PLG II).

2 Obra publicada originalmente na França, em 2012, com tradução publicada, no Brasil, em 2014. A autoria é atribuída a Benveniste, mas vale ressaltar que a obra foi editada a partir de notas preparatórias das aulas realizadas pelo autor e de anotações dos alunos que estavam presentes nas aulas ministradas.

3 Na versão original: "Il ne s'agit plus, cette fois, $\mathrm{du}$ signifié du signe, mais de ce qu'on peut appeler l'intenté, de ce que le locuteur veut dire, de l'actualisation linguistique de sa pensée" (BENVENISTE, 1974, p. 225, grifo nosso). Como se pode constatar, a versão brasileira de Problèmes de linguistique générale 2 traduziu intenté como intencionado e não como intenta$d o$, assim como traduziu, também, signification de l'intenté como significação intencionada e não como significação do intentado. Trata-se de um sentido realizado no discurso, como efeito da passagem da língua ao discurso; algo que revela um querer dizer do locutor, que envolve um pensamento que se atualiza em discurso e produz sentido.

\section{Referências}

BENVENISTE, Émile. Os níveis da análise linguística (1962/1964). In: . Problemas de linguística geral I. Tradução de Maria da Glória Novak e Maria Luísa Neri. Revisão de Isaac Nicolau Salum. 4. ed. Campinas, SP: Pontes, 1995.

. Problèmes de linguistique générale 2. Paris: Gallimard, 1974.

. A forma e o sentido na linguagem (1966/1967). In: ____. Problemas de linguística geral II. Tradução de Eduardo Guimarães et al. Revisão técnica da tradução de Eduardo Guimarães. Campinas, SP: Pontes, 1989a.

Estruturalismo e linguística (1968) In:___. Problemas de linguística geral II. Tradução de Eduardo Guimarães et al. Revisão técnica da tradução de Eduardo Guimarães. Campinas, SP: Pontes, 1989b.

. Semiologia da língua (1969). In: - Problemas de linguística geral II. Tradução de Eduardo Guimarães et al. Revisão técnica da tradução de Eduardo Guimarães. Campinas, SP: Pontes, 1989c.

. Últimas aulas no Collège de France

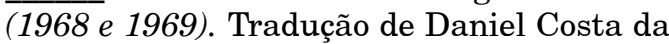
Silva et al. São Paulo: Editora Unesp, 2014.

FLORES, V. Introdução à teoria enunciativa de Benveniste. São Paulo: Parábola, 2013a.

. O que seria uma gramática da enunciação? A proposta de uma análise transversal. Enunciação, Subjetividade e Ensino, Letras \& Letras, Uberlândia, v. 29, n. 1, p. 1-7, $2013 \mathrm{~b}$. 